\title{
An Intelligent Modeling and Controller design for Clarifier process: A Metaheuristic Algorithm approach.
}

M Rajalakshmi

Jyothi Engineering College

C Karthik

Jyothi Engineering College

V Arunprasad

Theni Kammavar Sangam College of Technology

G Saravanakumar

Adisababa

Sanjeevi Pandiyan ( $\sim$ gpsanjeevi@jiangnan.edu.cn )

Jiangnan University https://orcid.org/0000-0002-1377-0456

\section{Research Article}

Keywords: Sugar Industry, Clarifier Process, pH neutralization, System Identification, GA, PSO, STA

Posted Date: April 12th, 2021

DOl: https://doi.org/10.21203/rs.3.rs-371226/v1

License: (9) This work is licensed under a Creative Commons Attribution 4.0 International License. Read Full License 


\section{Abstract}

This paper concentrates on the modeling and control of the sugar industry's nonlinear clarifier process. Since the sugar industry's clarification mechanism is complex and nonlinear, it is therefore important to obtain the exact model with identification methods. Using the normal modeling technique, the basic model of the complex process is obtained and further improved to make the model act like the actual system. The most accurate model from the algorithms is analysed using metaheuristic algorithms such as Genetic Algorithm (GA), Particle Swarm Optimization (PSO), and State Transition Algorithm (STA). The proposed STA design to the clarifier model provides the maximum fitness. The clarifier model derived from State Transition Algorithm (STA) behaves more similar to the actual clarifier process by capturing the principle dynamic qualities of the process. Simulations have demonstrated that STA is an optimum algorithm for the clarifier process than the other algorithms. From the results, it is inferred that the controllers introduced in this study, can be utilized to accomplish a better performance than the standard controller design, and during the control of any nonlinear procedure and STA is extremely helpful in modeling a nonlinear process.

\section{Full Text}

This preprint is available for download as a PDF.

\section{Figures}




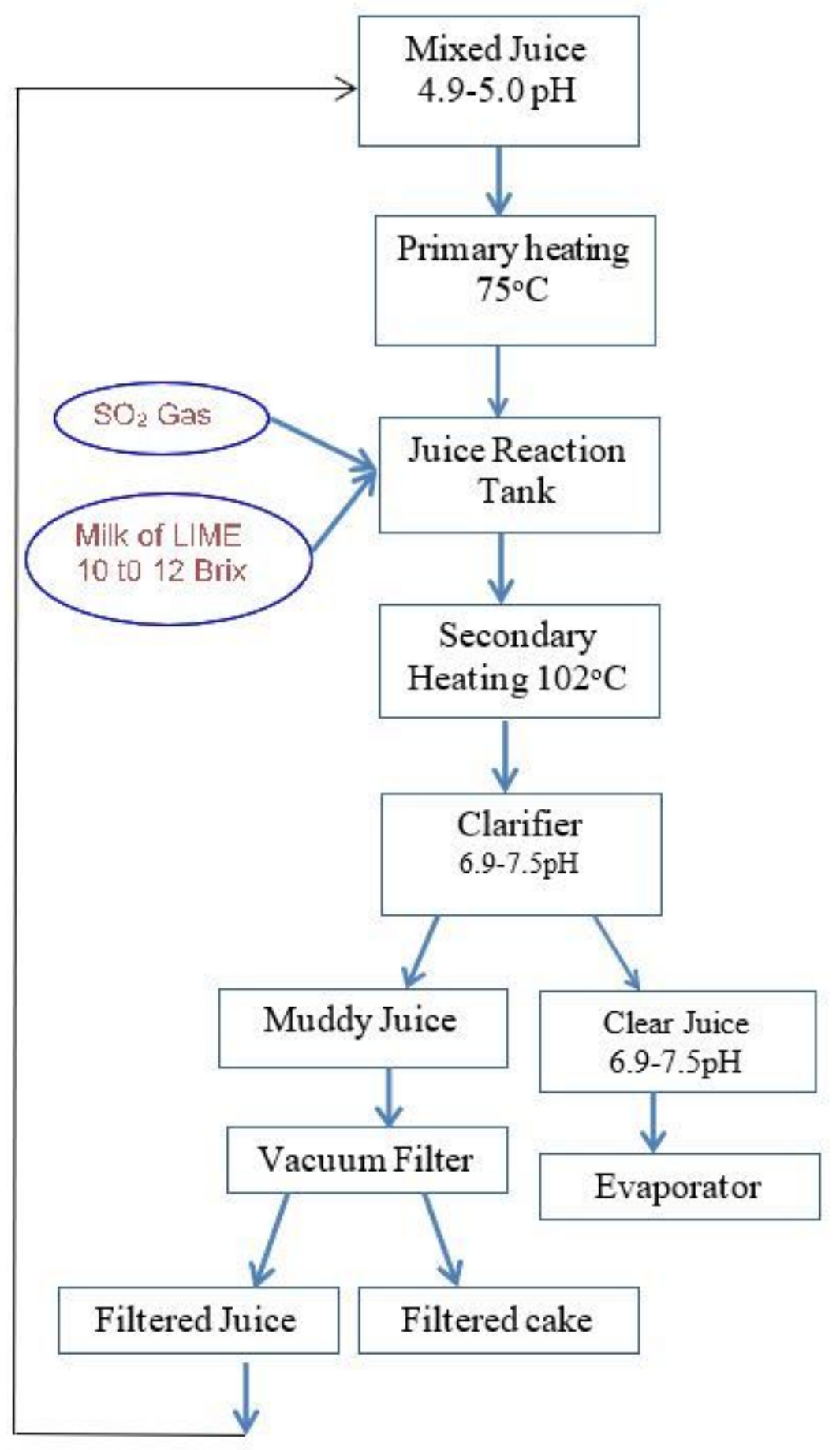

Figure 1

Clarifying process flow diagram 


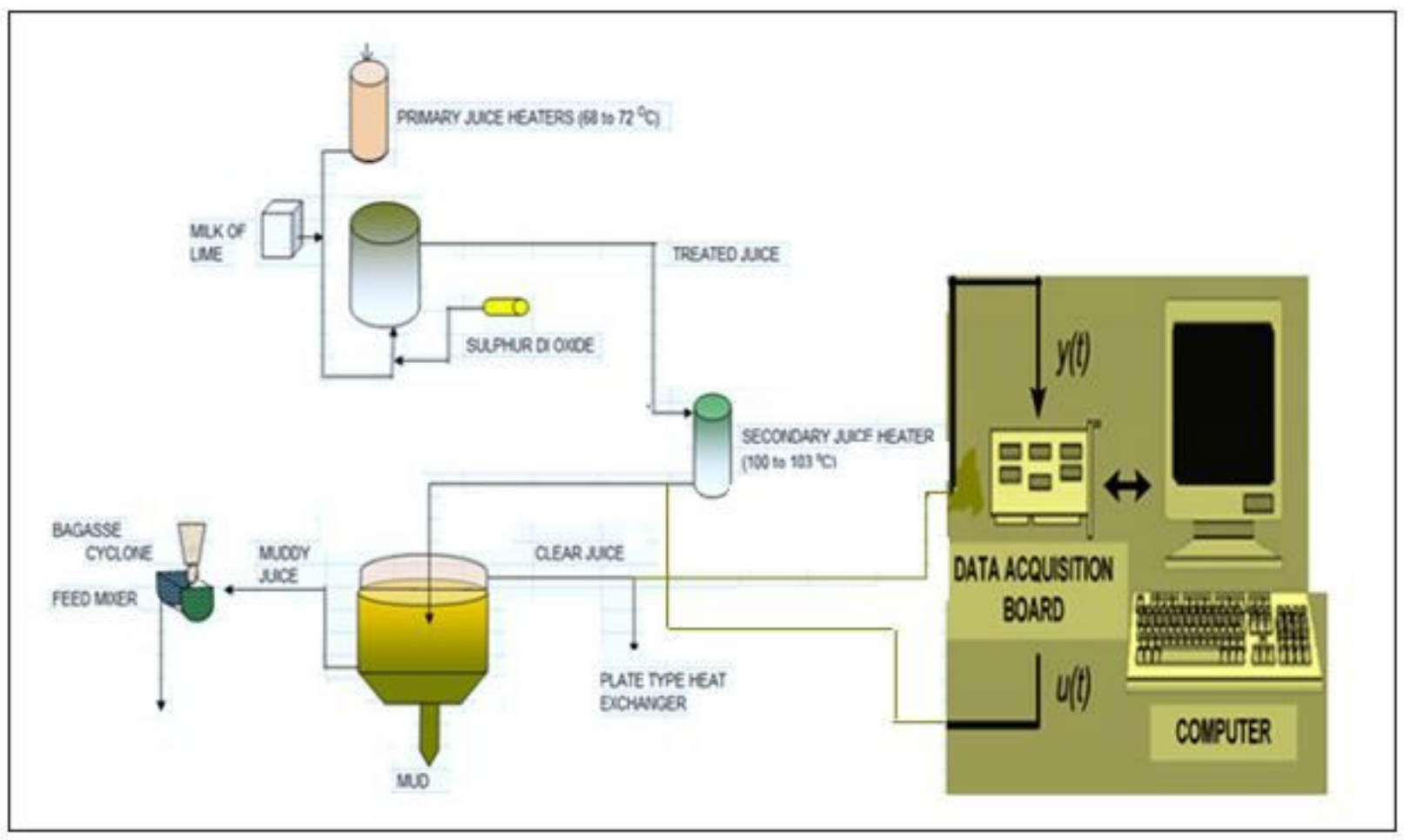

Figure 2

Time calculation and data collection of the clarifying process
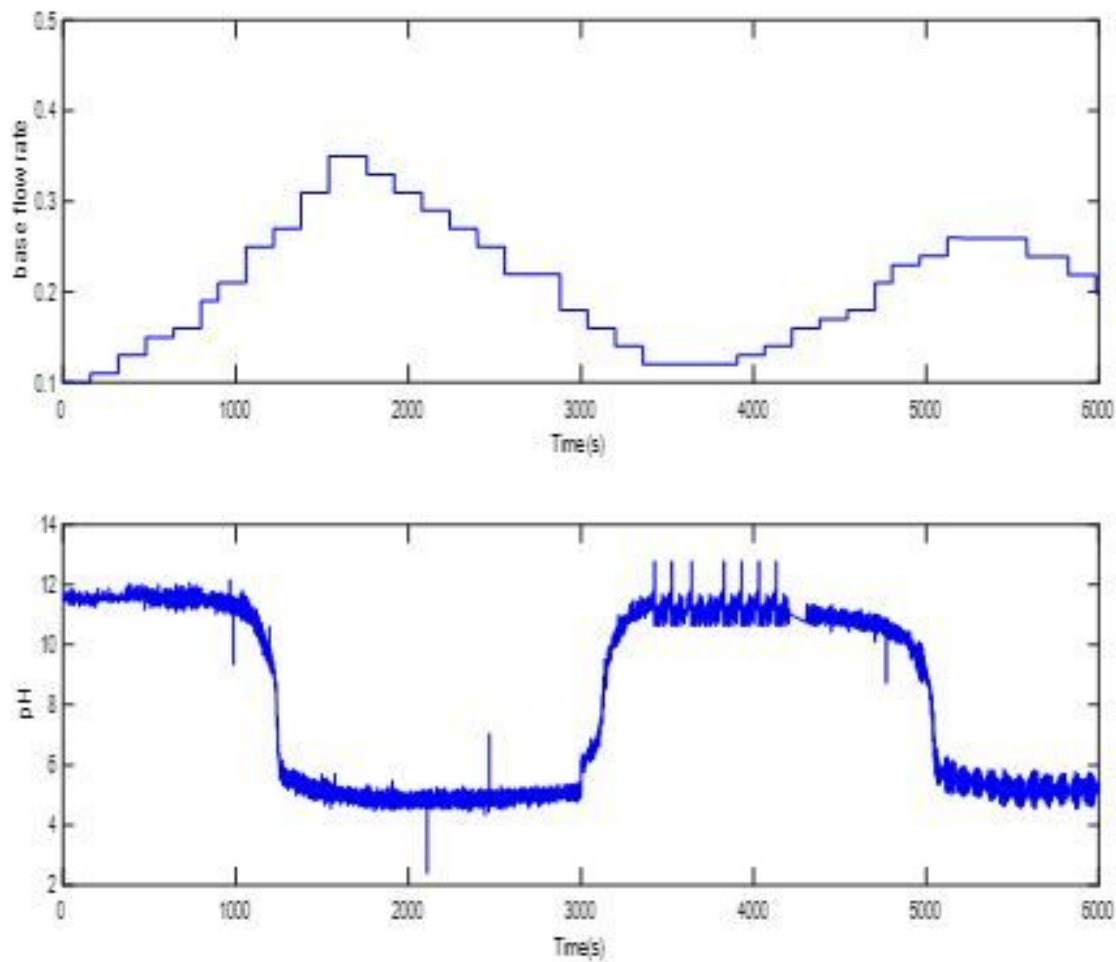

Figure 3

Input and output collection of clarifier process 


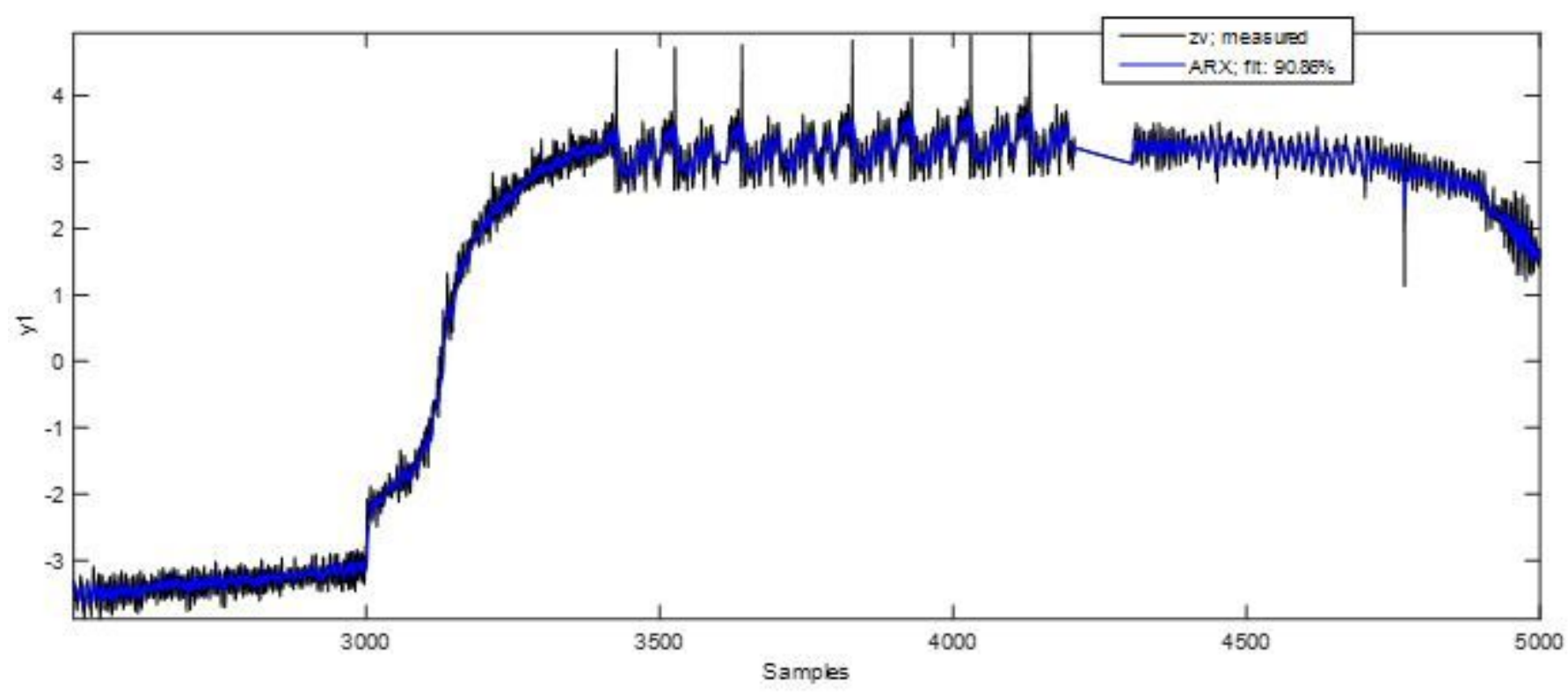

Figure 4

Validation response of ARX model

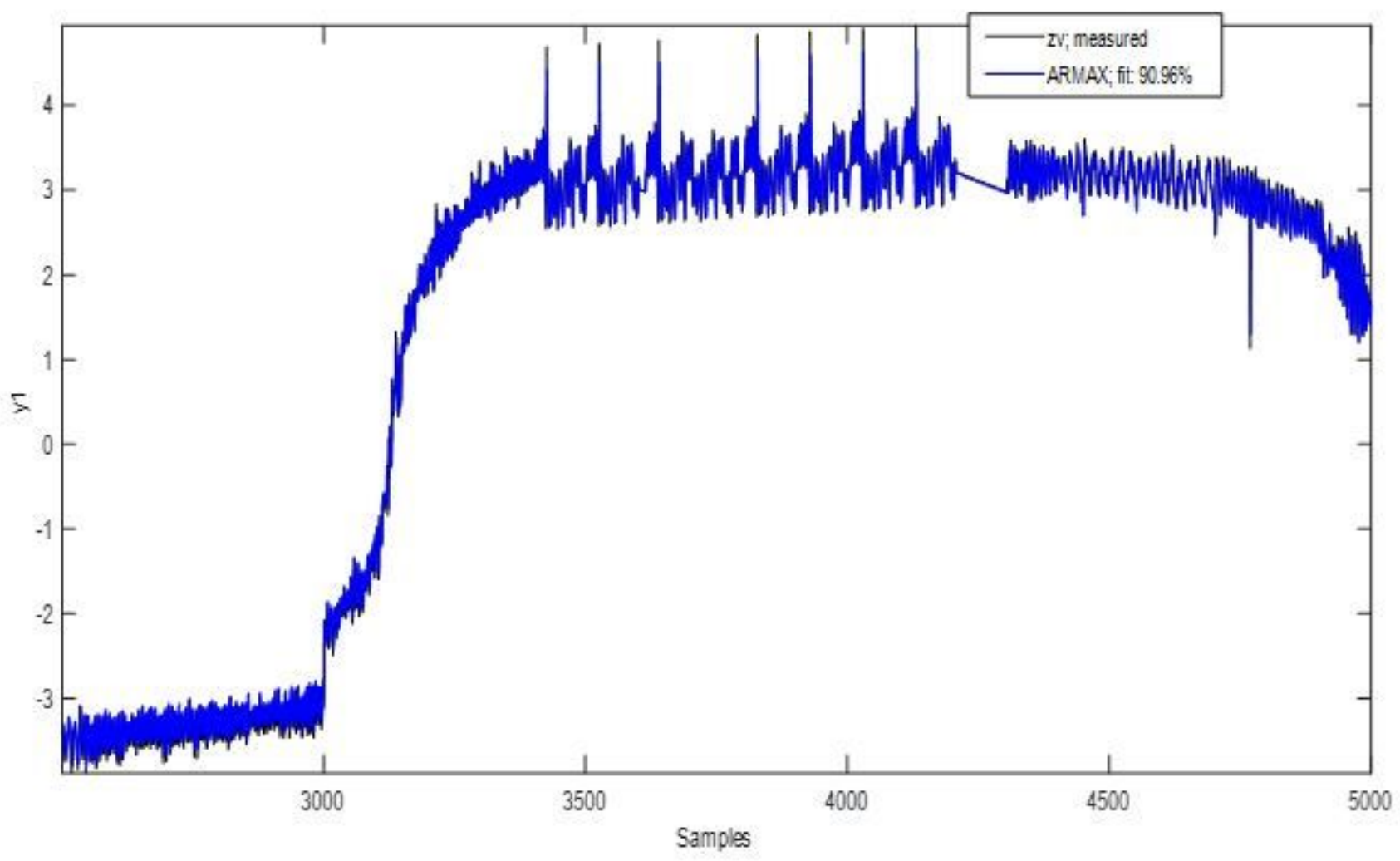

Figure 5

Validation response of ARMAX model 


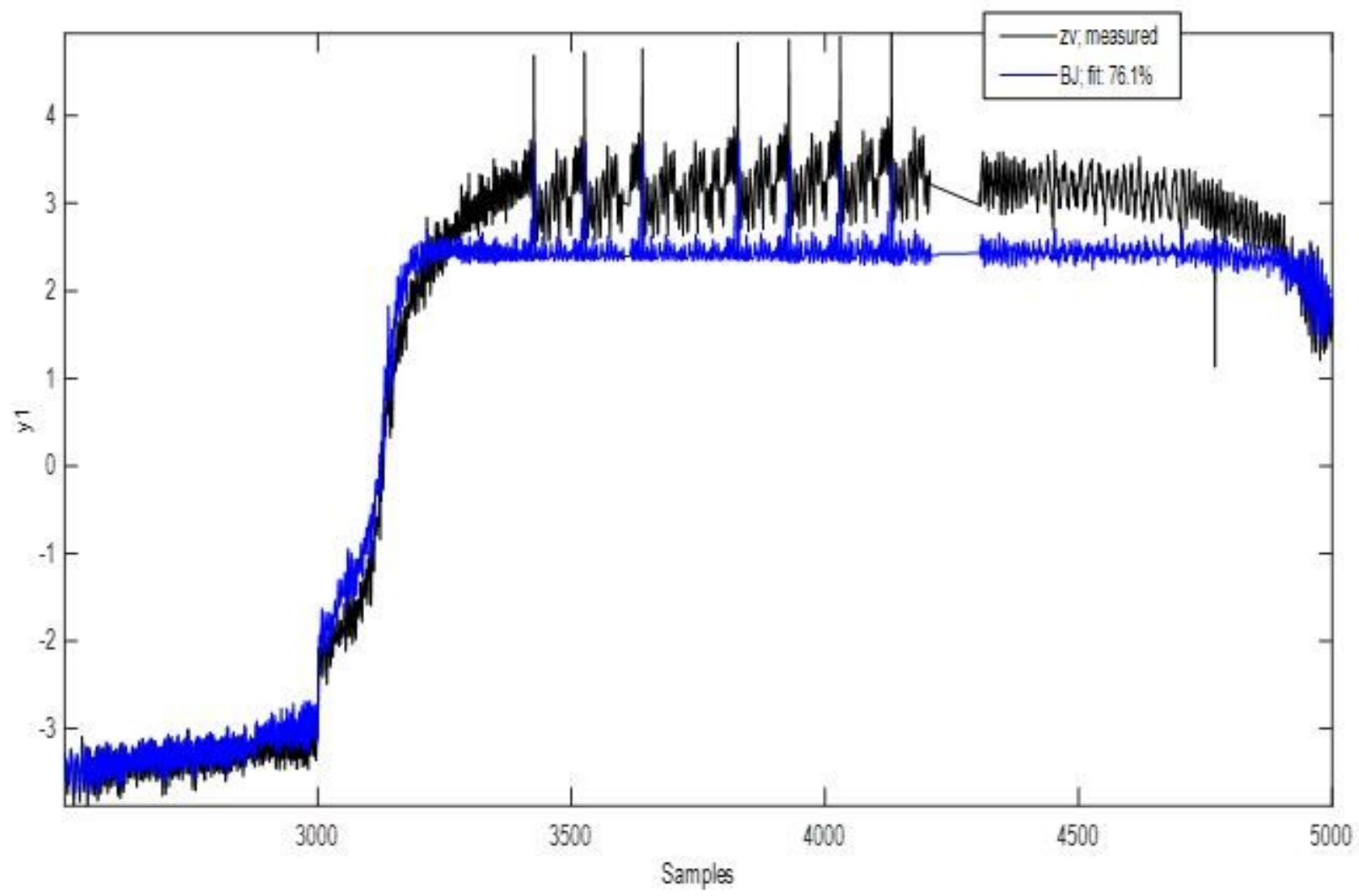

Figure 6

Validation response of box jenkin model

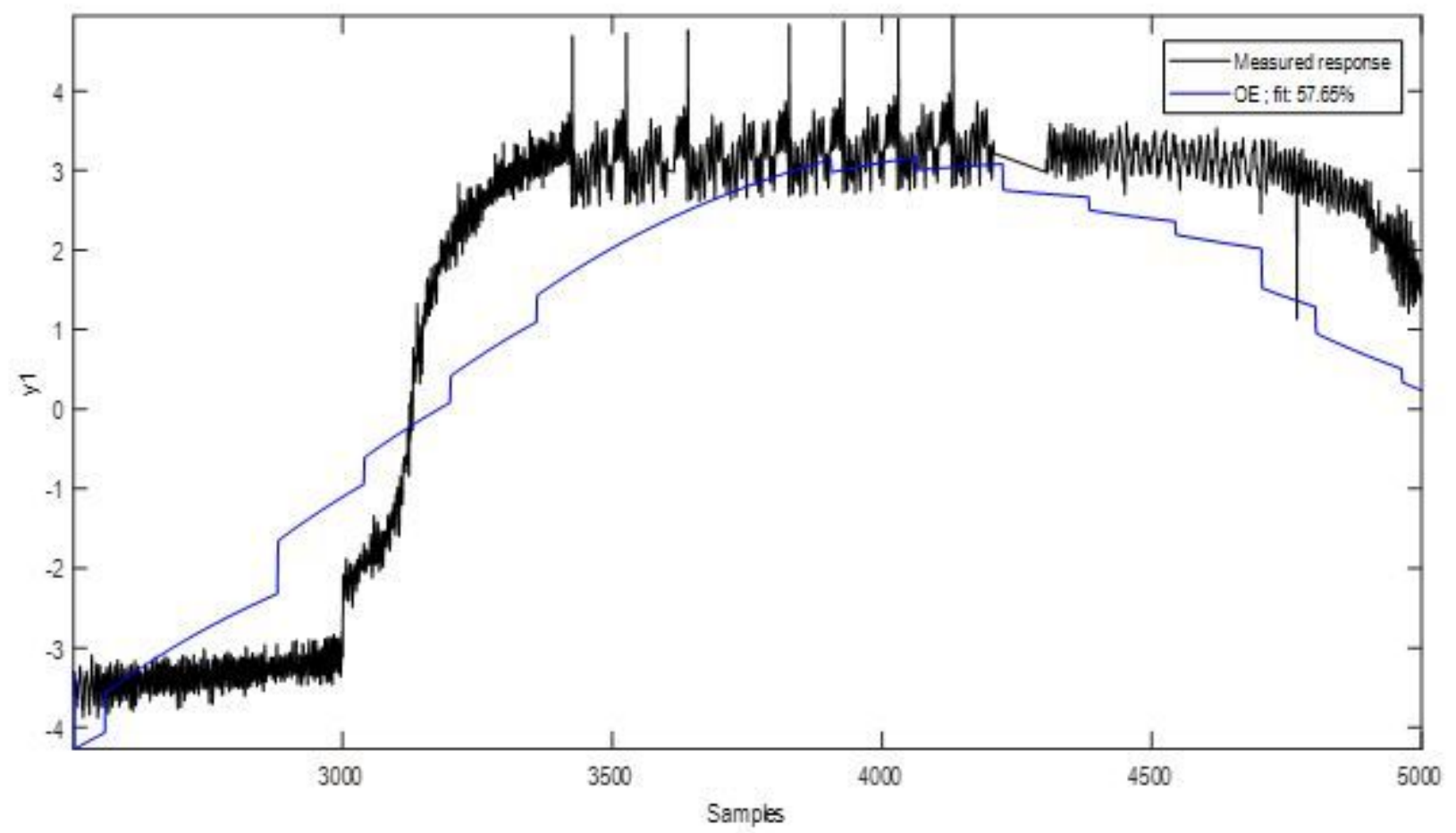

Figure 7 
Validation response of OE model

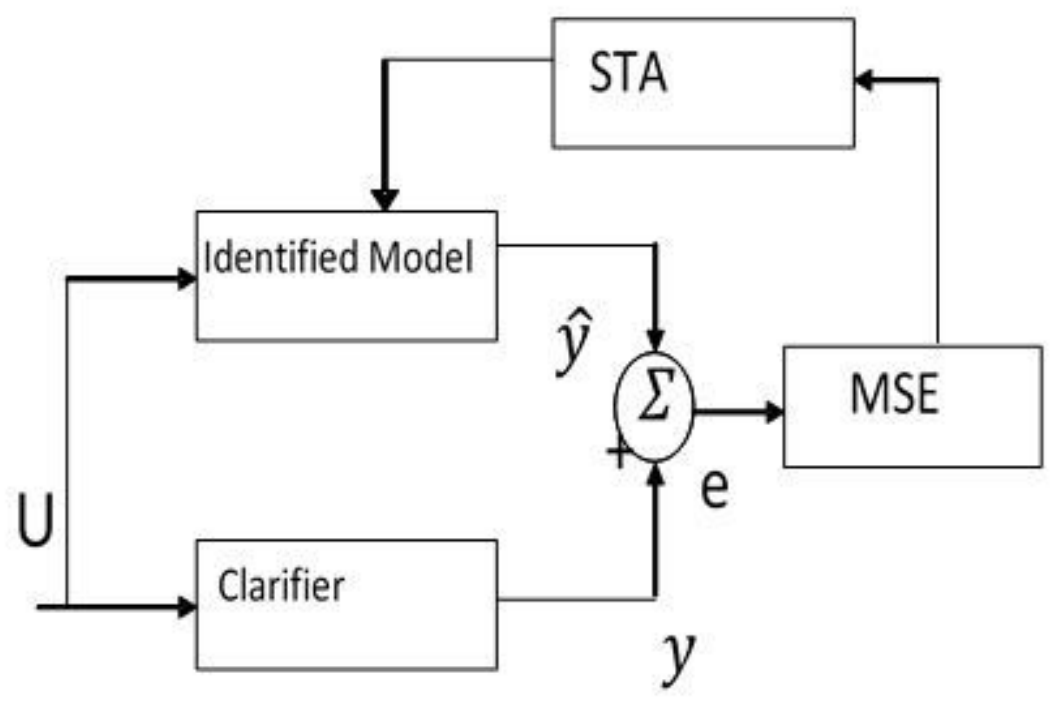

Figure 8

STA in parameter identification
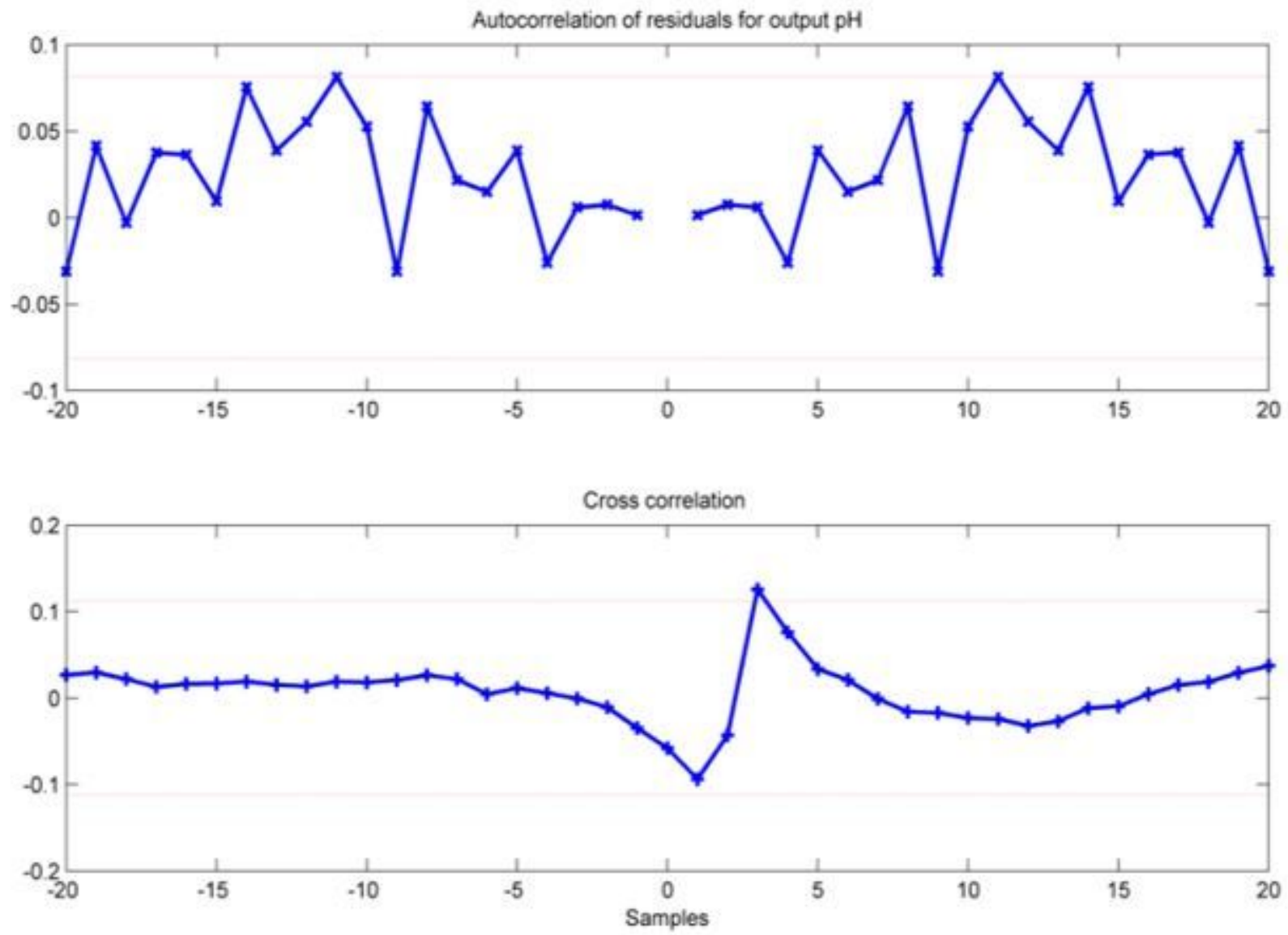

Figure 9 
The residual analysis of the identified ARMAX model
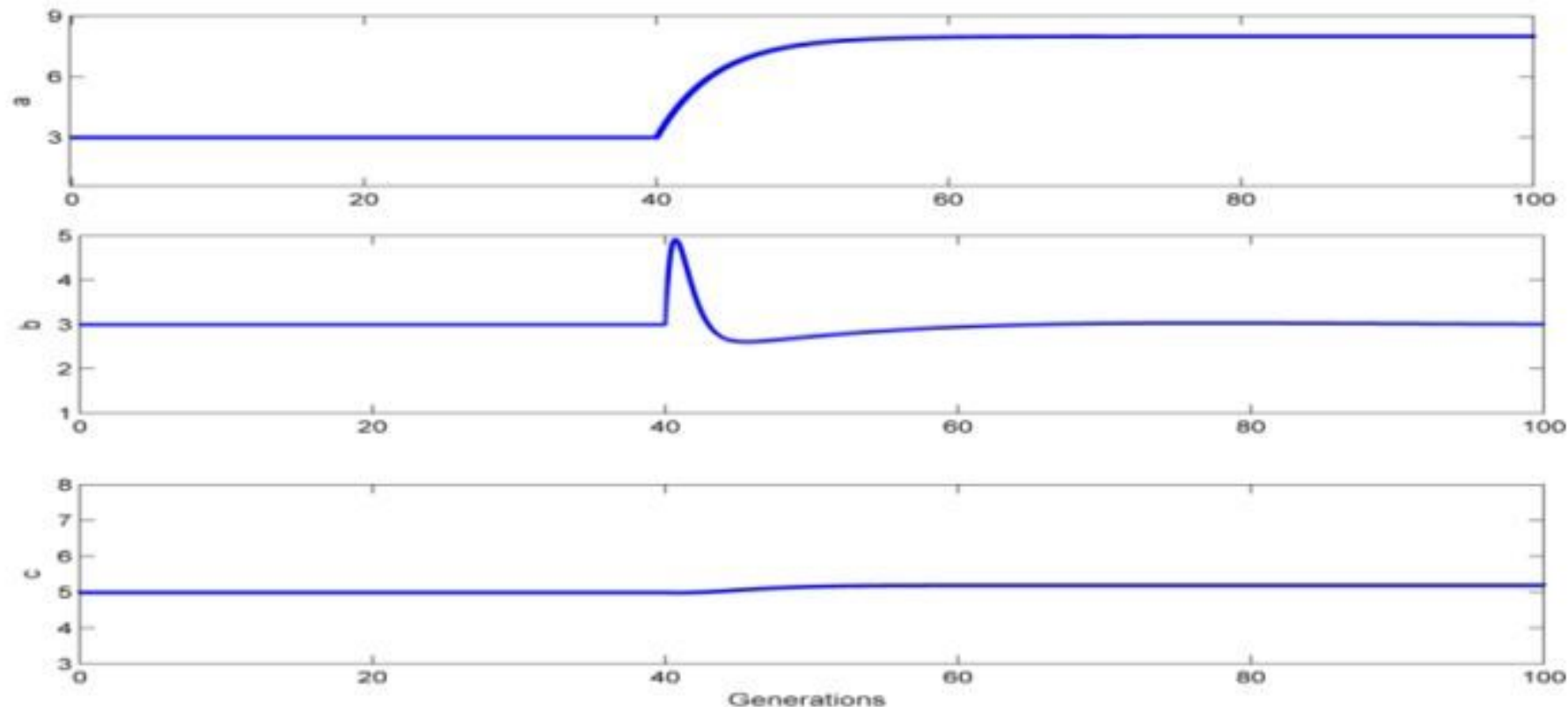

\section{Figure 10}

Convergence of model parameter by STA tuning

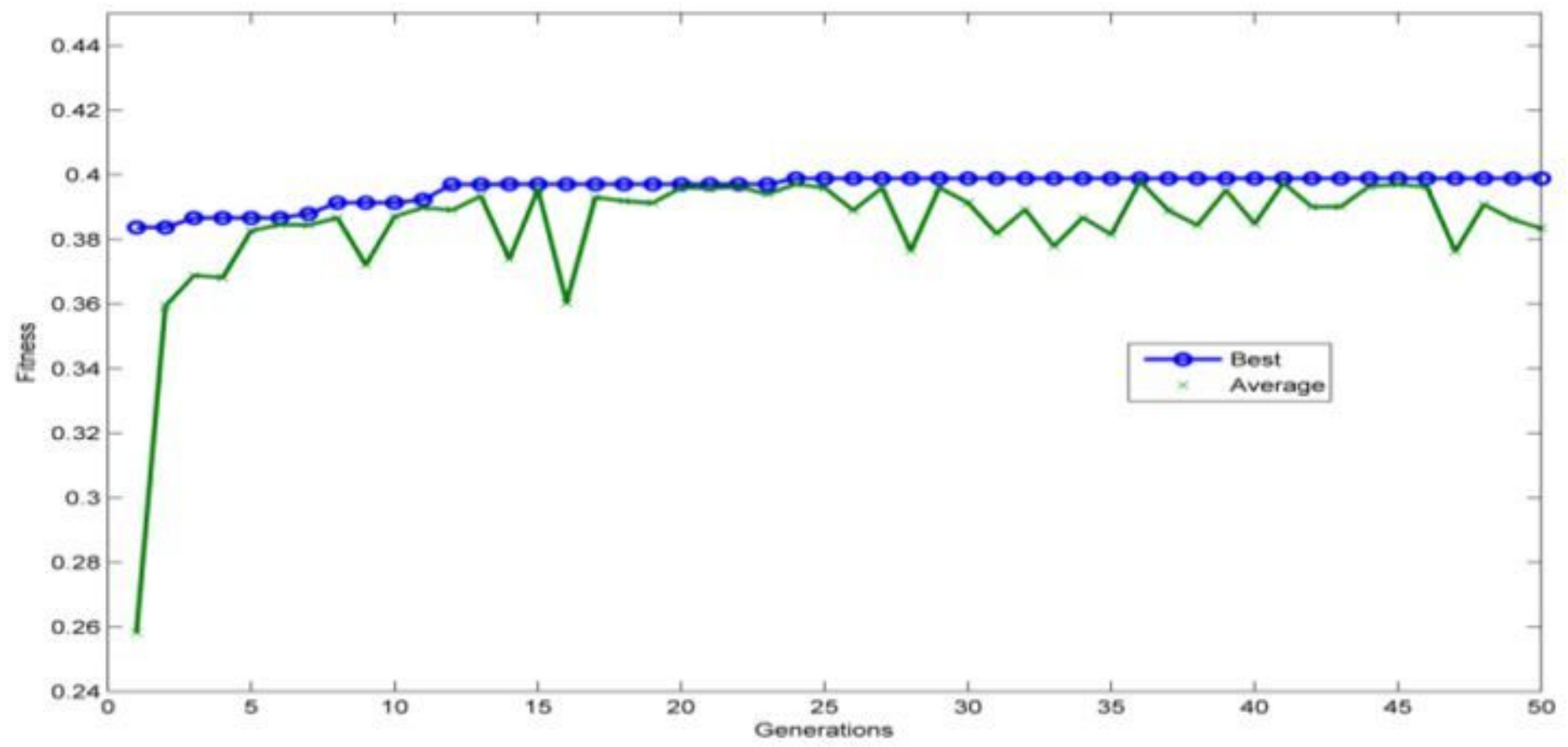

\section{Figure 11}

Convergence of fitness 


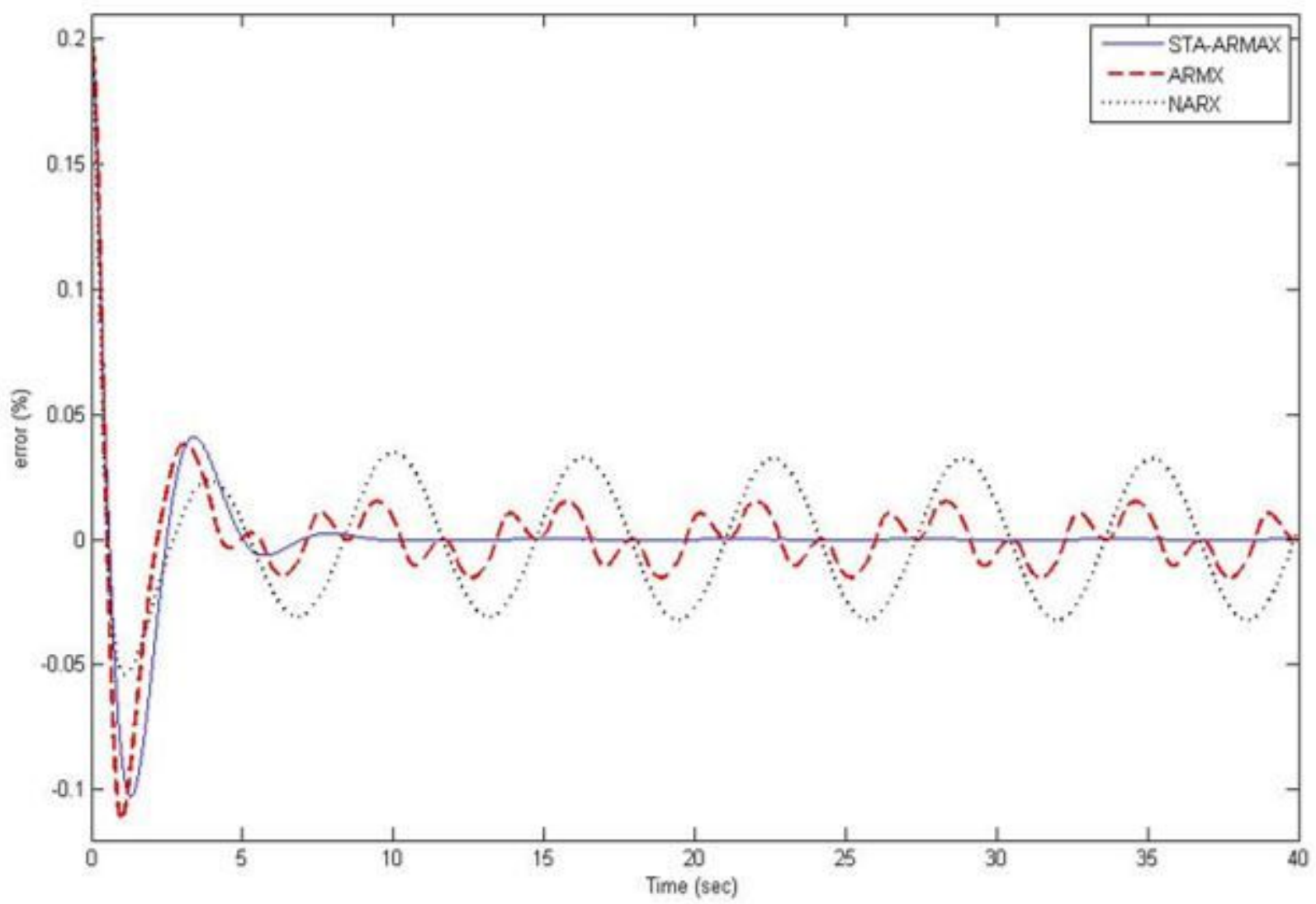

Figure 12

Model error of various identification methods 


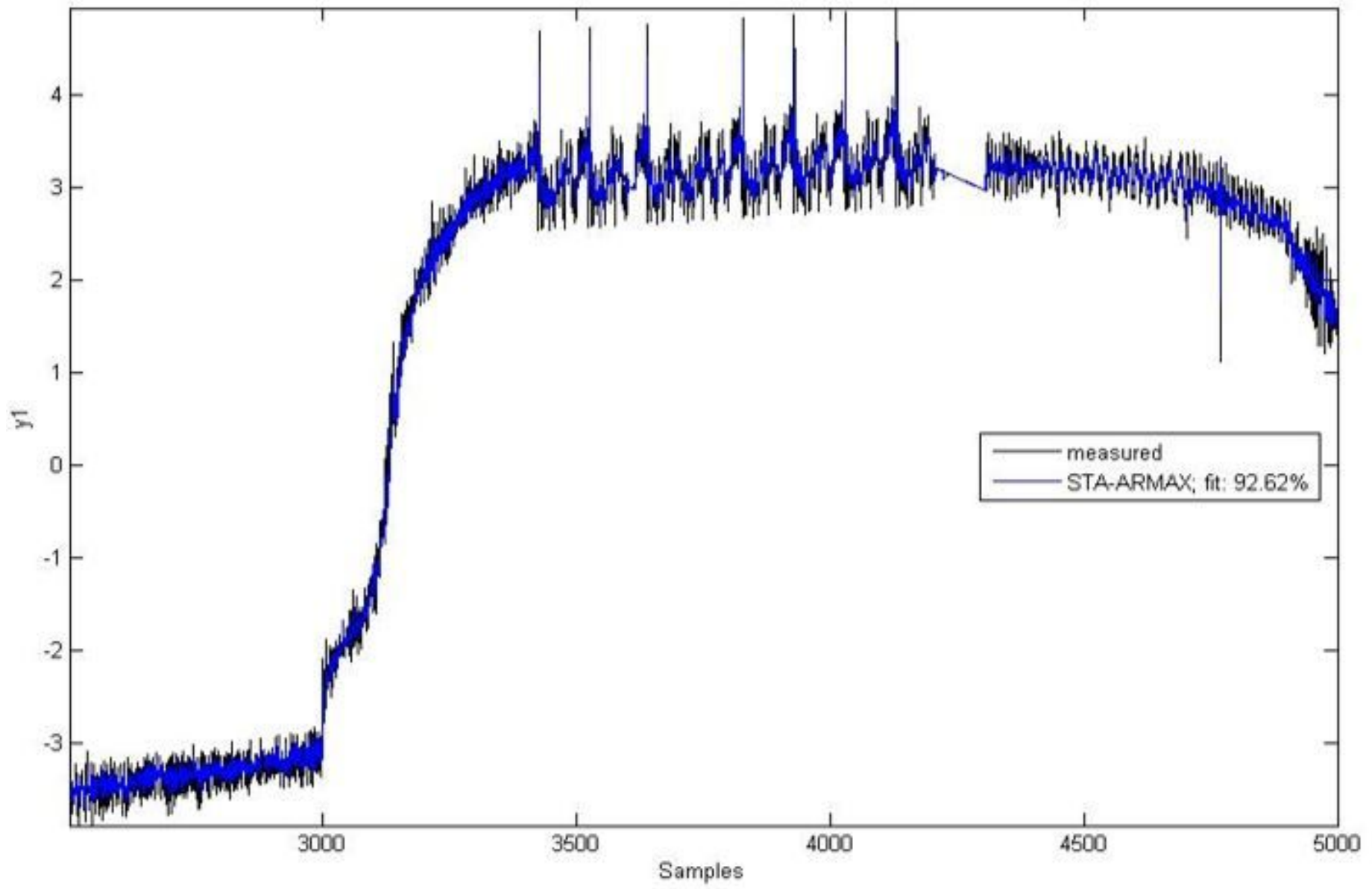

Figure 13

Identified model using the STA - ARMAX method 


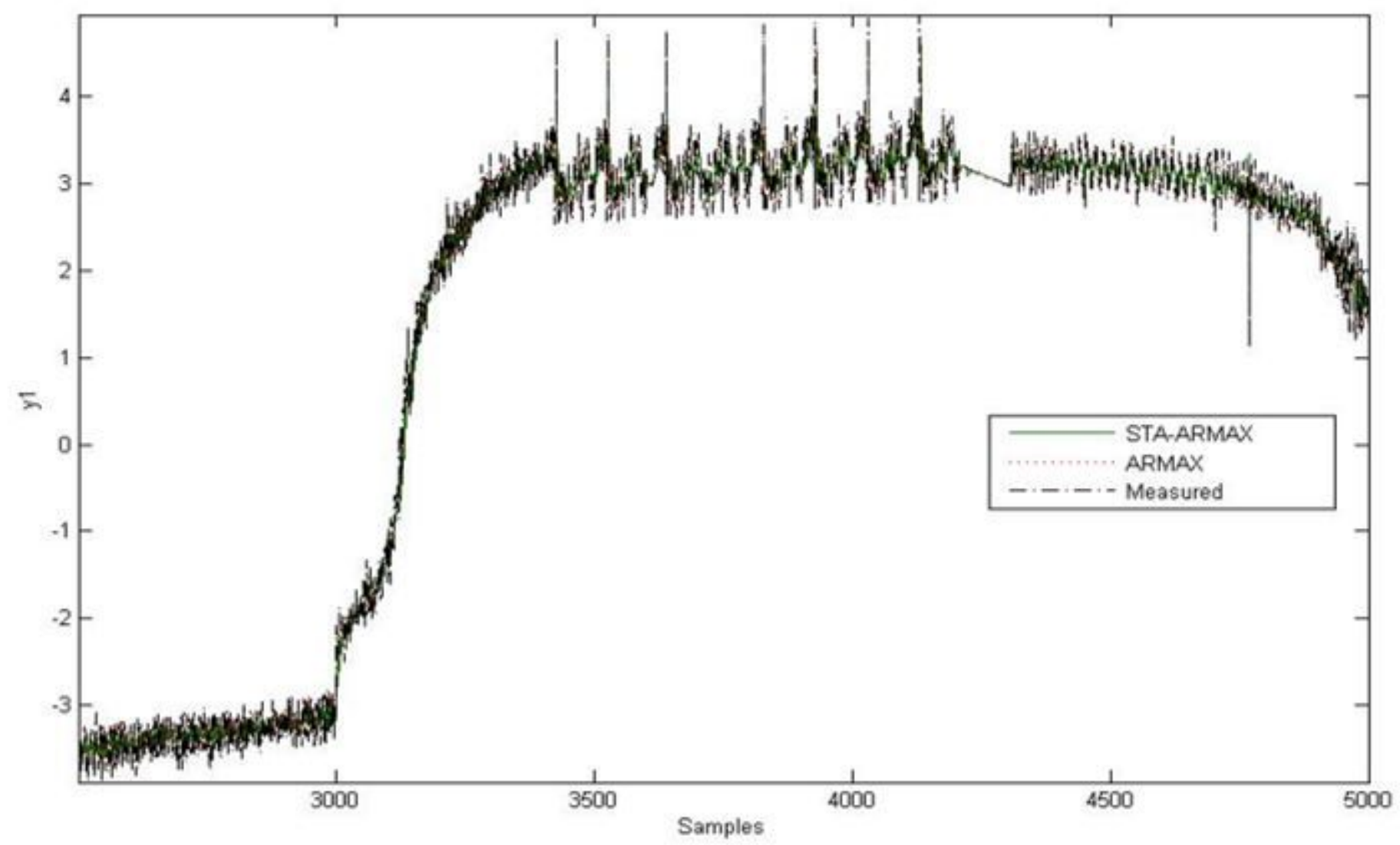

Figure 14

Comparative model analysis of various methods

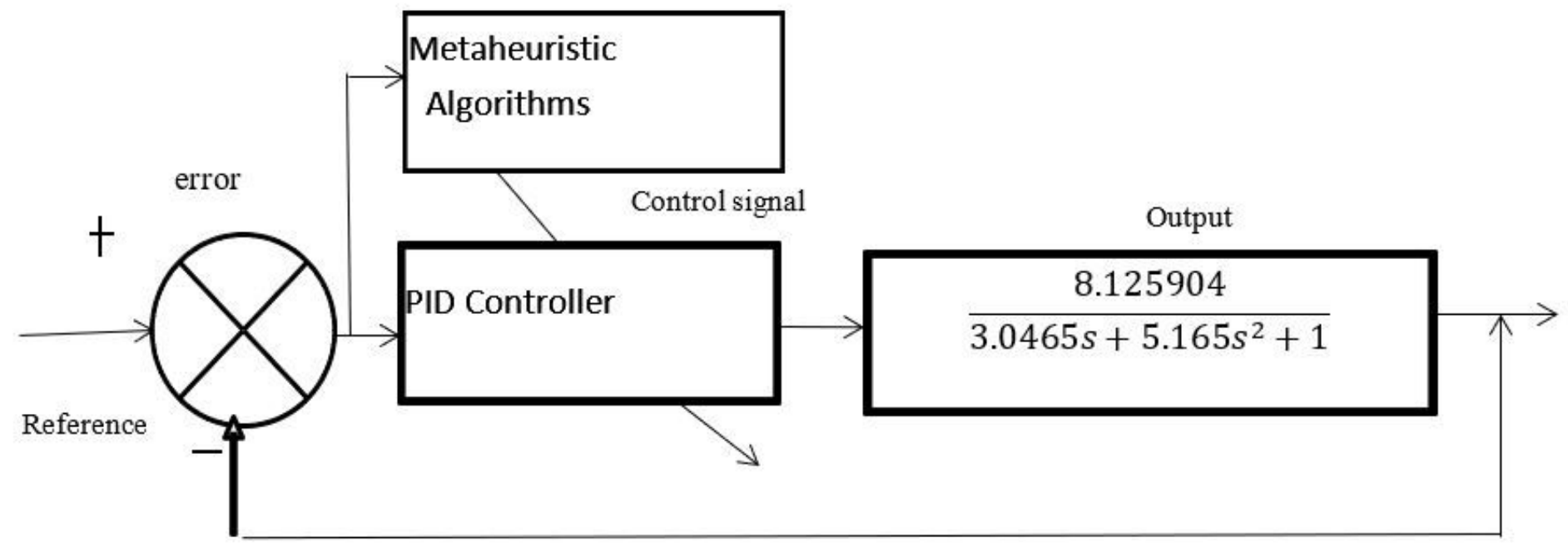

Figure 15

Design of closed loop control 


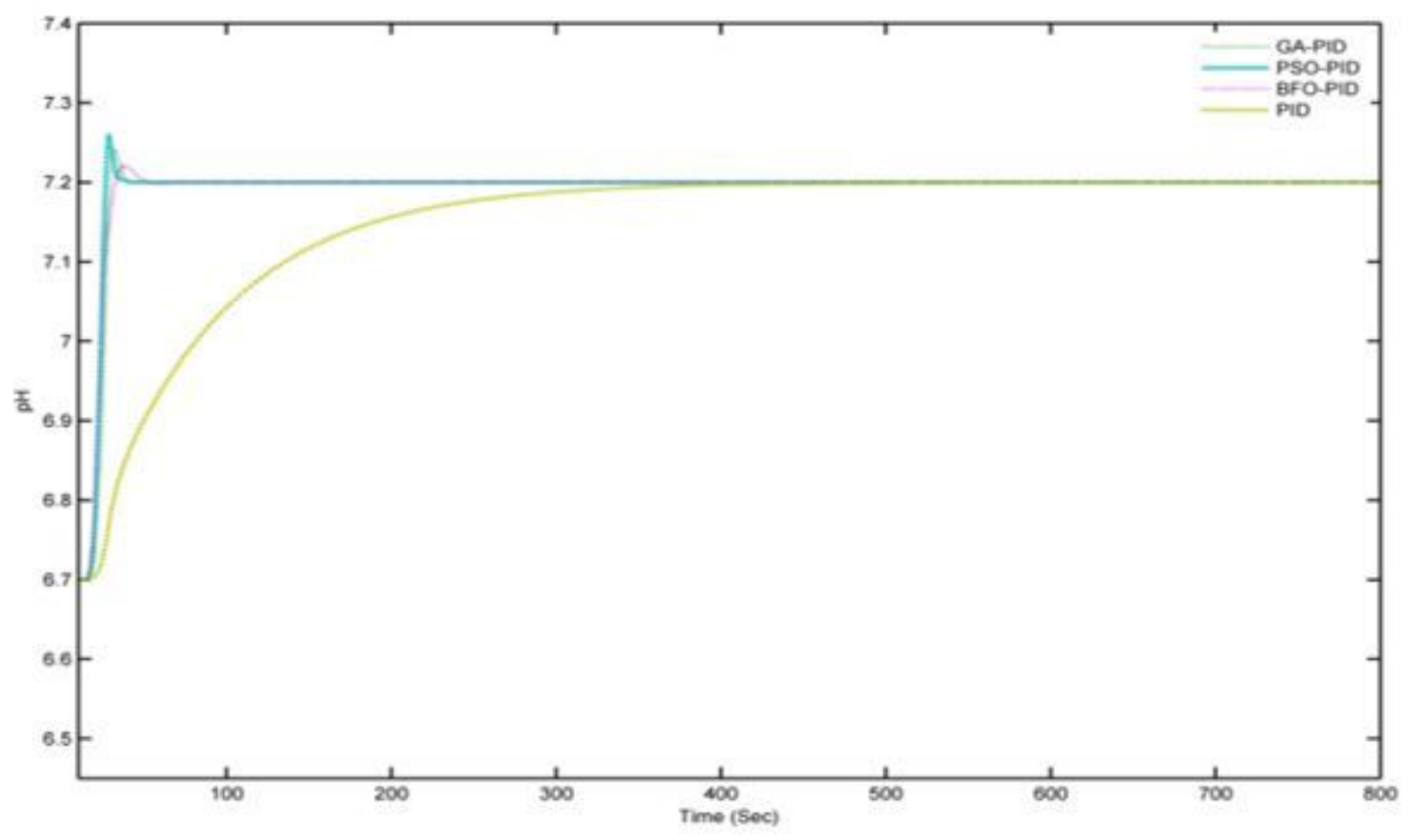

Figure 16

Conventional controller performances

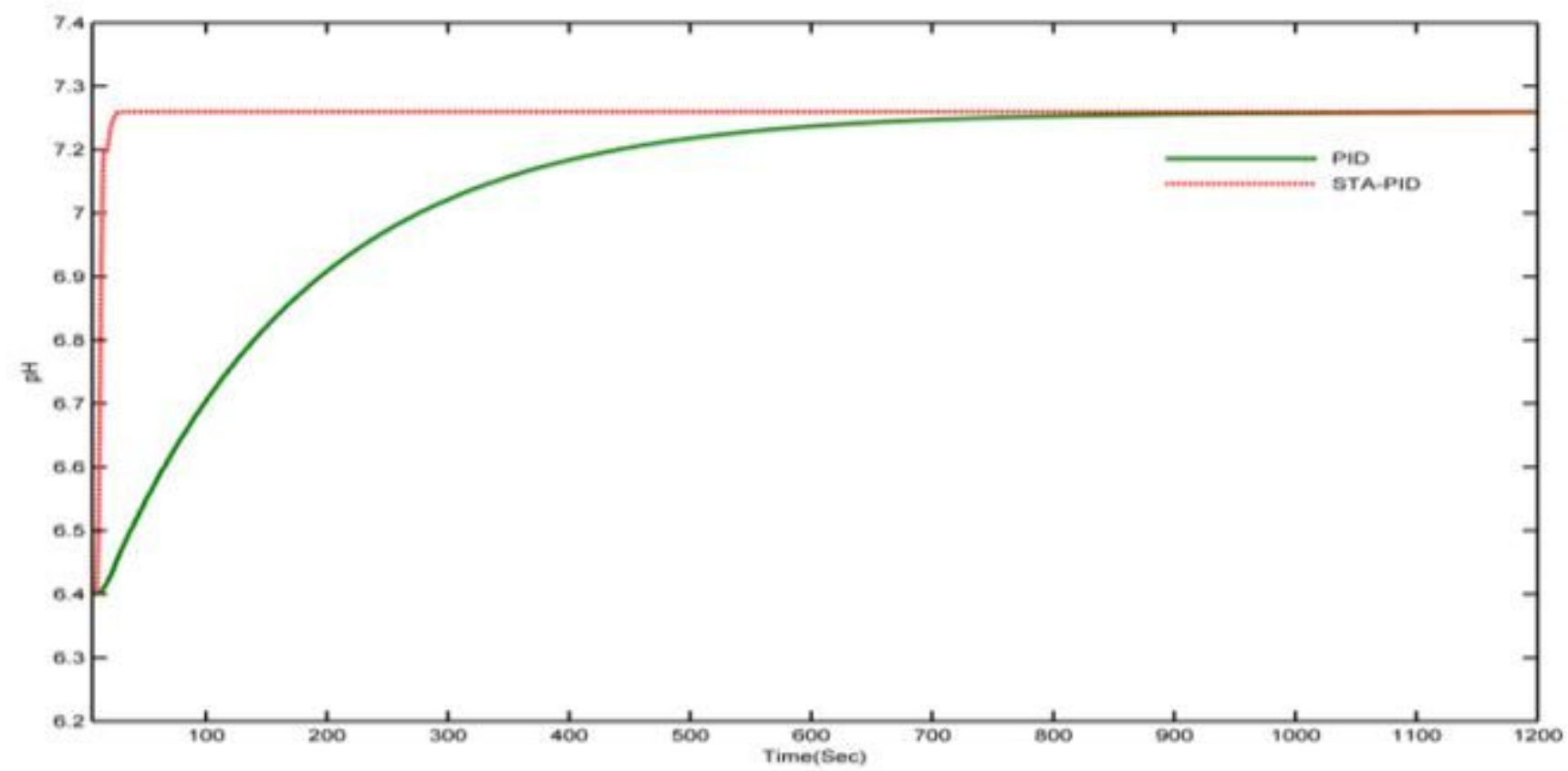

Figure 17

Comparative analysis of STA-PID and PID 


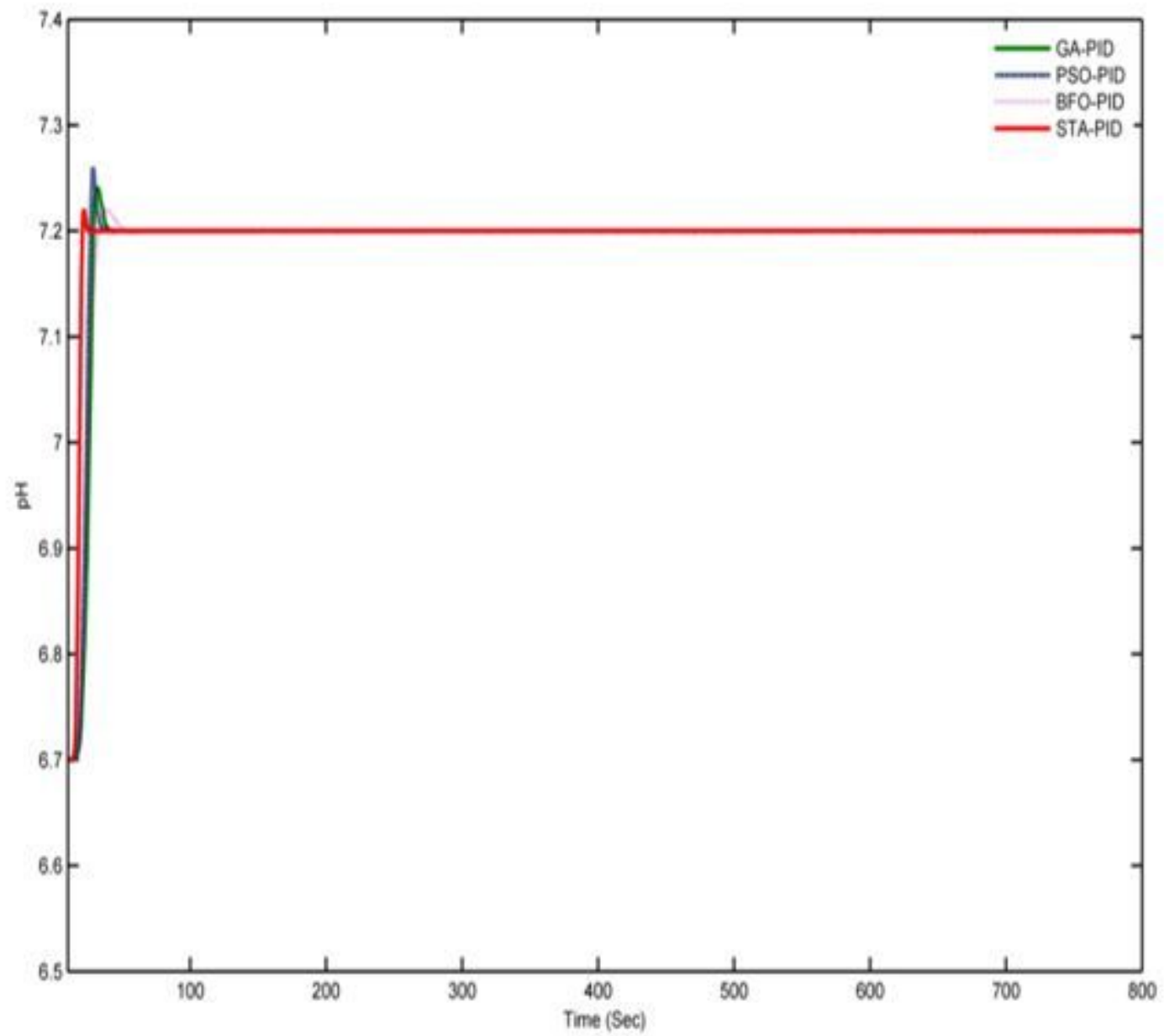

Figure 18

Controller performances to a unit step function 


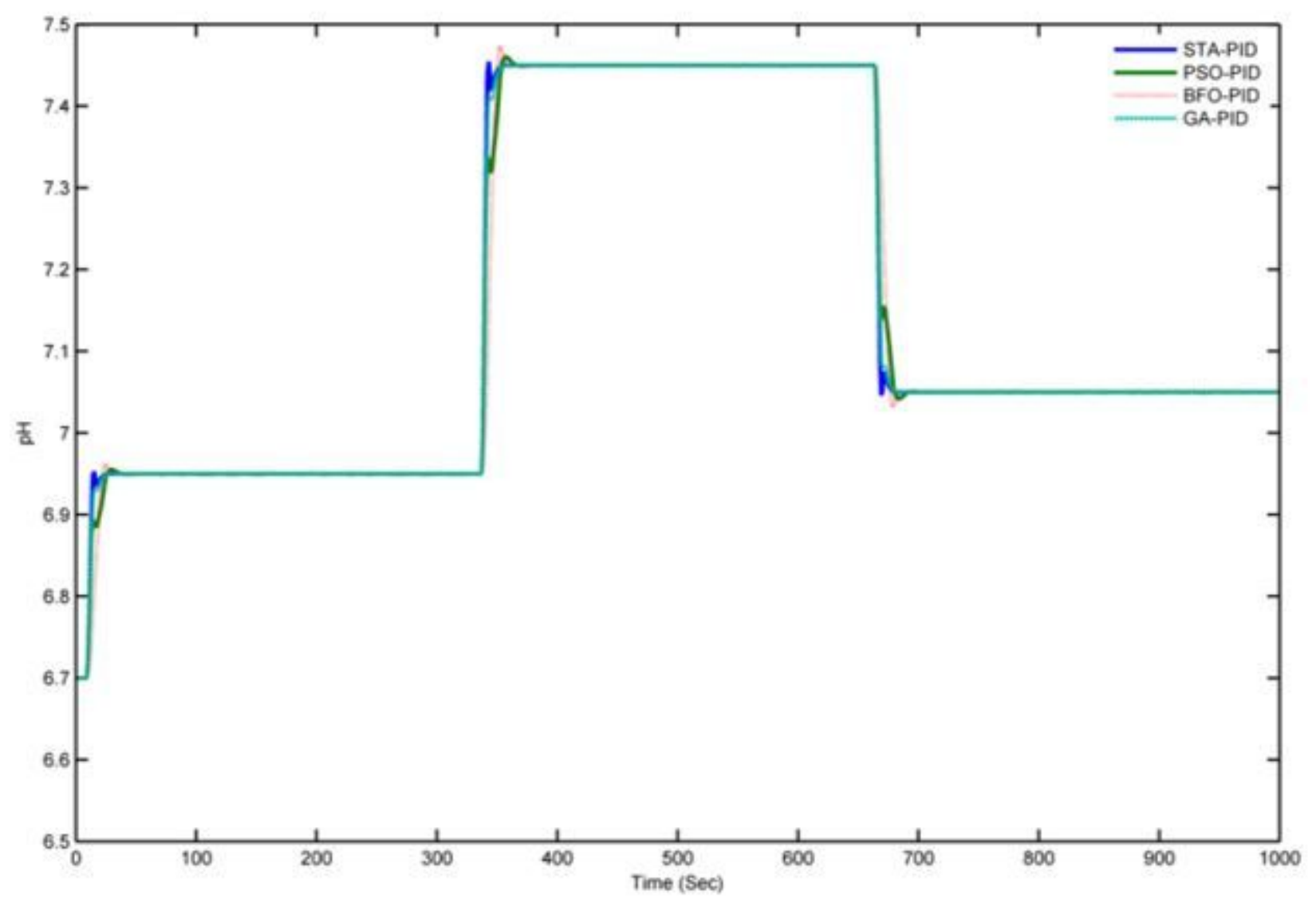

Figure 19

Servo performance measures of various controllers

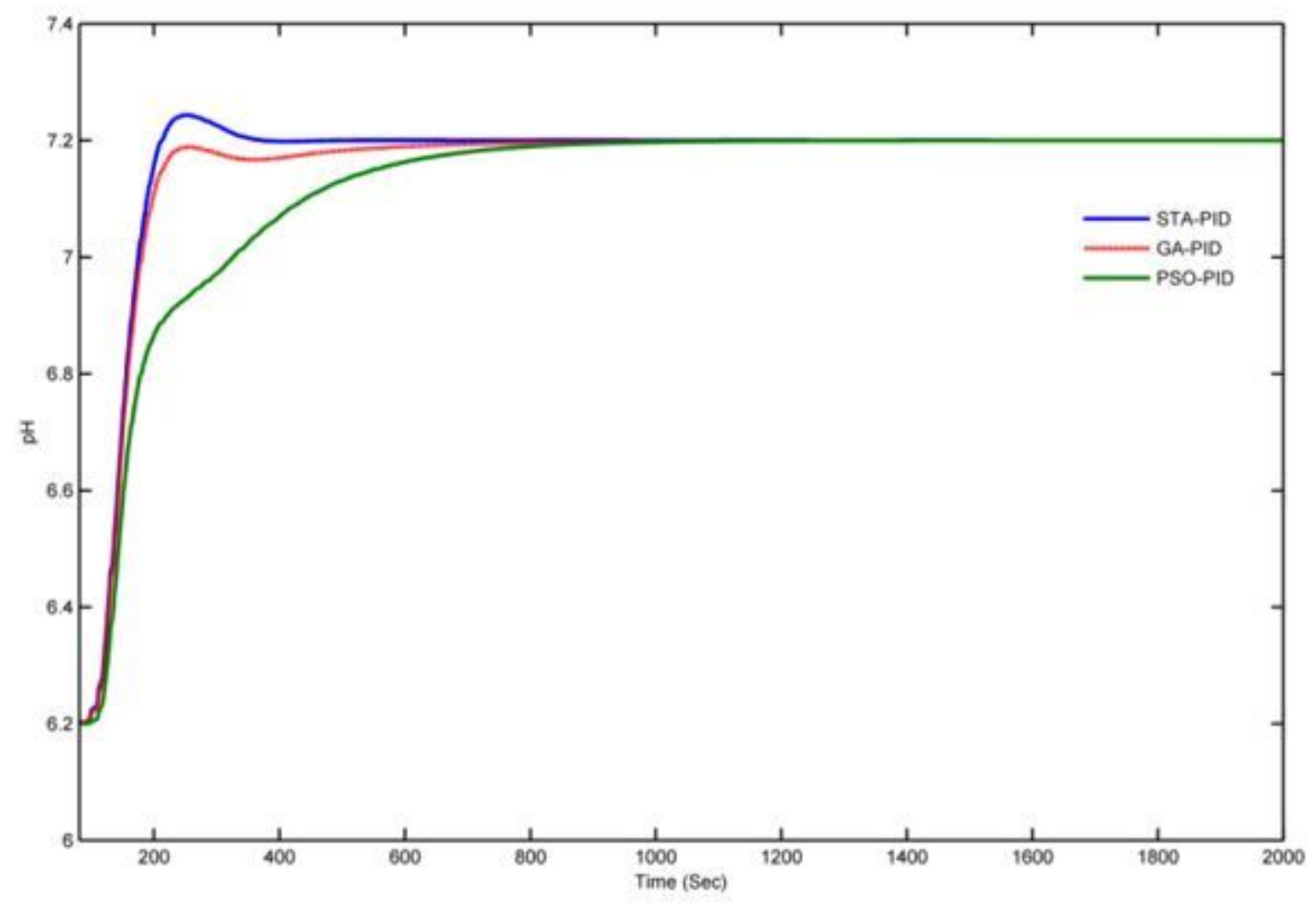

Page 14/16 
Figure 20

Response of STA-PID controller to the system

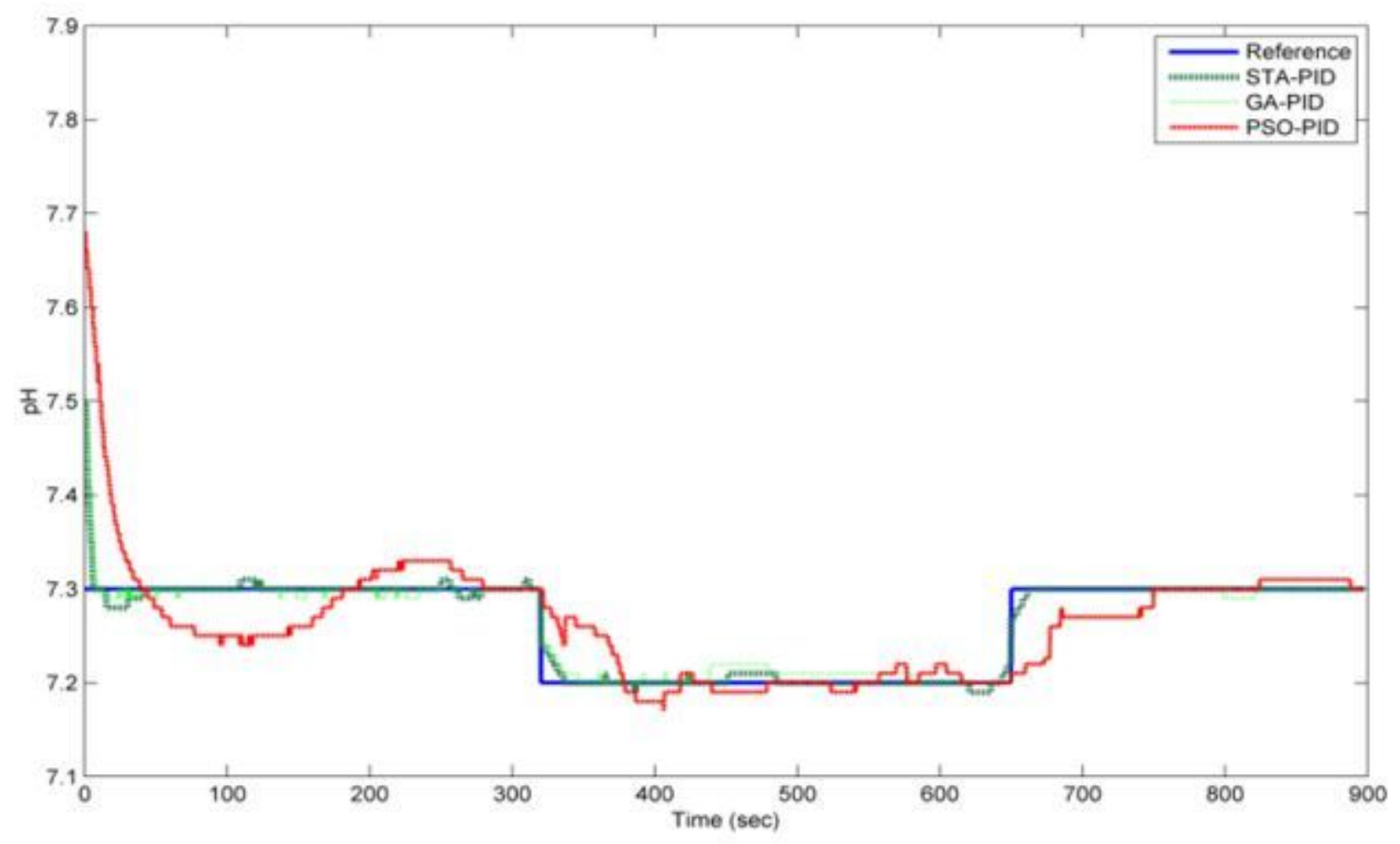

Figure 21

Servo performances of various proposed controllers 

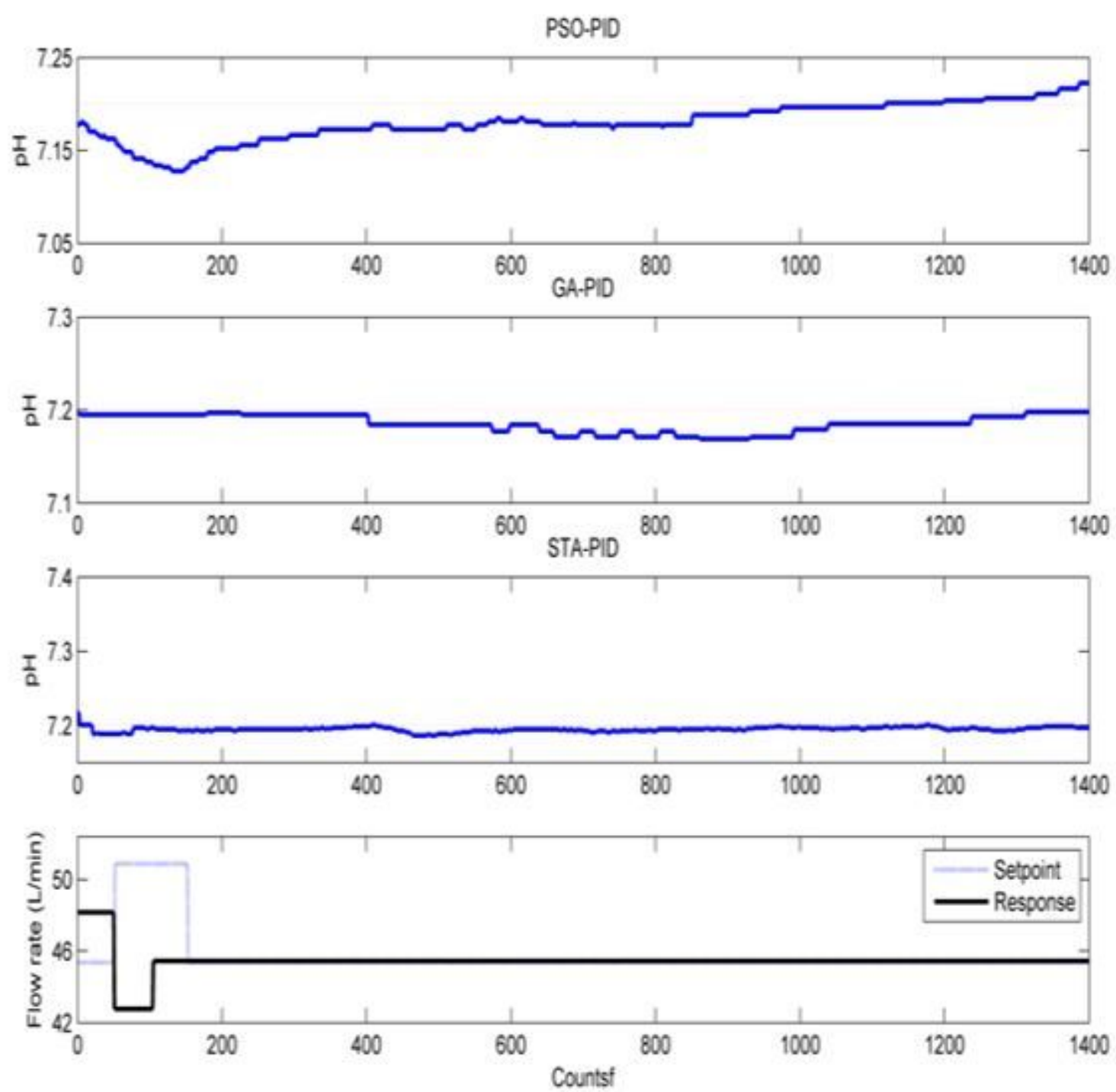

Figure 22

Disturbance rejection response of various controllers 